\title{
The Association between 5HT2A T102C and Behavioral and Psychological Symptoms of Dementia in Alzheimer's Disease: A Meta-Analysis
}

\author{
Liang Tang, ${ }^{1,2}$ Yan Wang, ${ }^{1,2,3}$ Yiwei Chen, ${ }^{1,2}$ Lianghui Chen, ${ }^{1,2,3}$ Shui Zheng, ${ }^{4}$ Meihua Bao, ${ }^{1,2}$ \\ Ju Xiang, ${ }^{1,2}$ Huaiqing Luo, ${ }^{1,2,3}$ Jianming Li, ${ }^{1,5}$ and Yungui Li ${ }^{6}$ \\ ${ }^{1}$ Department of Human Anatomy, Histology and Embryology, Institute of Neuroscience, Changsha Medical University, \\ Changsha, China \\ ${ }^{2}$ School of Basic Medical Science, Changsha Medical University, Changsha, China \\ ${ }^{3}$ Experiment Center for Function, Changsha Medical University, Changsha, China \\ ${ }^{4}$ Key Laboratory for Fertility Regulation and Birth Health of Minority Nationalities of Yunnan Province, Judicial Expertise Center, \\ Yunnan Population and Family Planning Research Institute, Kunming, China \\ ${ }^{5}$ Department of Neurology, Xiangya Hospital, Central South University, Changsha City, Hunan Province, China \\ ${ }^{6}$ Department of Biological Science, Hunan Environment Biological Polytechnic, Hengyang, China \\ Correspondence should be addressed to Jianming Li; ljming0901@sina.com and Yungui Li; yglcsmu@126.com
}

Received 6 June 2017; Accepted 8 October 2017; Published 16 November 2017

Academic Editor: Helen F. K. Chiu

Copyright (c) 2017 Liang Tang et al. This is an open access article distributed under the Creative Commons Attribution License, which permits unrestricted use, distribution, and reproduction in any medium, provided the original work is properly cited.

\begin{abstract}
The serotonin receptor gene (5-HT2A) has been reported to be a susceptible factor in behavioral and psychological symptoms of dementia (BPSD) in Alzheimer's disease (AD). However, previous results were conflicting. We aim to investigate the association of 5-HT2A T102C with BPSD in AD using a meta-analysis. Studies were collected using PubMed, Web of Science, the Cochrane Library databases, Chinese National Knowledge Infrastructure (CNKI), and Embase. Pooled odds ratios (ORs) with 95\% confidence intervals (CIs) were used to assess associations. Nine studies with $1899 \mathrm{AD}$ patients with/without BPSD were included in this metaanalysis. The 102C and CC genotypes were associated with psychosis in AD (102C: $p<0.00001$, OR [95\% CI] = 3.19 [2.12-4.79]; CC: $p<0.00001$, OR $[95 \% \mathrm{CI}]=7.24$ [3.60-14.59]). The TT genotype was significantly associated with hallucinations, aberrant motor behavior, and psychosis in $\mathrm{AD}$ (hallucinations: $p=0.001, \mathrm{OR}[95 \% \mathrm{CI}]=0.52[0.36-0.77]$; aberrant motor behavior: $p=0.03, \mathrm{OR}$ $[95 \% \mathrm{CI}]=0.58[0.35-0.95]$; and psychosis: $p=0.002$, OR $[95 \% \mathrm{CI}]=0.34[0.17-0.67])$. No association was observed between T102C alleles or genotypes and delusions, agitation/aggression, depression, and apathy $(p>0.05)$. Thus, the 5HT2A T102C might be a susceptible factor for hallucinations, aberrant motor behavior, and psychosis in $\mathrm{AD}$. The potential mechanism of this polymorphism in BPSD in AD requires further exploration.
\end{abstract}

\section{Introduction}

Cognitive decline is one of the major neuropsychiatric features in Alzheimer's disease (AD) [1]. However, a variety of other neuropsychiatric features, such as depression, delusions, hallucinations, aberrant motor behavior (AMB), and anxiety, known as the behavioral and psychological symptoms of dementia (BPSD), are also present [2]. The incidence of BPSD is not consistent in AD patients. To date, the aetiology for BPSD in AD is not clear yet. Studies have been proposed that these symptoms may be related to the loss of different neuronal populations, such as the parahippocampal gyrus and the dorsal raphe nucleus, specific neurotransmitters, including dopamine and serotonin, and genetic components [3-5].

Serotonin (5-hydroxytryptamine, 5-HT) is a key neurotransmitter involved in many aspects of human and animal behavior, including aggression, hallucinations, delusions, depression, anxious behavior, and the regulation of appetite [6-8]. The action of $5-\mathrm{HT}$ is mediated by $5 \mathrm{HT}$ receptors, 
especially 5HT2A and 5HT2C, which have been previously examined as possible factors for susceptibility to certain aspects of BPSD and many other psychiatric diseases, such as bipolar affective disorder and schizophrenia [9-12]. Moreover, postmortem and biopsy studies have shown changes in the expression levels and receptor binding of 5-HT receptors in brains of $\mathrm{AD}$ patients [13]. Consequently, many studies have examined the relationship between several polymorphisms of serotonin genes, especially the 5HT2A gene, and psychotic symptoms in $\mathrm{AD}$ patients. Recent observations indicate that a silent mutation presenting at position 102 (T102C) in this receptor gene may be a risk factor for psychotic symptoms in the course of AD.

Holmes et al. [14] firstly reported the association between the 5-HT2A C102 polymorphism and the hallucinations in $\mathrm{AD}$, which was subsequently confirmed by Nacmias et al. in an European population [15]. Rocchi et al. reported the significant association between 5-HT2A C102 and psychosis [16], which was also followed by Lam et al. in a Chinese cohort [17]. In addition, the $5 \mathrm{HT} 2 \mathrm{~A} 102 \mathrm{C}$ is also reported to be associated with schizophrenia $[18,19]$, agitation [14, 17], apathy [17], AMB [17], and depression [20] in AD. Similarly, the 5HT2A T102 was reported to be associated with delusions [21], agitation [21], and depression [20] in AD. However, Micheli et al. [22] proposed that 5HT2A $\mathrm{C} 102 \mathrm{~T}$ may not be involved in psychosis in $\mathrm{AD}$. And no statistically significant differences in the distributions of allele and genotype frequencies were found between $\mathrm{AD}$ patients with and AD patients without psychotic symptoms by Scordo et al. [23] and Pritchard et al. [24].

Due to the conflicting findings and limited availability of sample numbers in some studies, we aim to investigate the genetic associations between 5HT2A C102T and BPSD in AD patients by a meta-analysis.

\section{Materials and Methods}

2.1. Literature Search. Two independent authors (Liang Tang and Jianming Li) searched the PubMed, Embase, Web of Science, the Cochrane Library databases, and Chinese National Knowledge Infrastructure (CNKI) databases within the published years before 31 February, 2017, on the association between 5HT2A polymorphism and BPSD in Alzheimer's disease. The following terms were used in searching: "5HT2A" or "neurotransmitter 5-hydroxytryptophan $2 \mathrm{~A}$ Receptor" or "serotonin receptor $2 \mathrm{~A}$ " or "Serotonin $2 \mathrm{~A}$ Receptor" or "HTR2A" and "Alzheimer's disease" or "AD" and "behavioral and psychological symptoms of dementia" or "BPSD" and "psychological symptom" and "polymorphism" or "polymorphisms". Meanwhile, other potentially relevant literature was identified by manual search of references of eligible studies. No language was restricted.

\subsection{Eligibility Criteria}

Inclusion Criteria. They were as follows: (1) The publication was an unrelated case-control study. (2) The study examines the association of 5HT2A T102C and psychological symptoms of $\mathrm{AD}$. (3) The genotype in the control group satisfied the Hardy-Weinberg equilibrium (HWE). (4) The frequencies of alleles or genotypes in the case and control groups could be extracted.

Exclusion Criteria. They were as follows: (1) repeat studies; (2) abstracts, letters, reviews, or editorial articles; (3) publications that did not fit the inclusion criteria.

2.3. Data Extraction. Data from the identified studies were extracted independently by Yan Wang and Shui Zheng using a standardized extraction form. Any disagreements were resolved through discussion among the authors to achieve a consensus. The following information was recorded for each study: first author, year of publication, ethnicity, assessment, number of patients with/without psychological symptoms, types of BPSD, positive results in each study, number of alleles, and genotype.

2.4. Quality Assessment. The quality of individual studies was assessed independently by two reviewer (Fang Li and Ju Xiang) according to the Jadad scale [25]. Four items were assessed, including source of controls, specimens, sample size, and evidence of $\mathrm{HWE}$. The quality scores ranged from 0 to 5 ( 0 being the lowest and 5 being the highest). Only studies with a score of 3 or higher were included.

2.5. Statistical Methods. The odds ratio (OR) and 95\% confidence interval (95\% CI) were calculated for evaluating the association between 5HT2A T102C and BPSD in AD risk using the RevMan 5 (Oxford, UK) and STATA12.0 (StataCorp, College Station, TX, USA). The pooled ORs were calculated using the $\mathrm{C}$ versus $\mathrm{T}$, TT versus $\mathrm{CT} / \mathrm{CC}$, and $\mathrm{CC}$ versus TT/CT genetic models. The statistical significance of the OR was determined using the $Z$ test. Statistical heterogeneity was tested using $\chi^{2}$-based $Q$ test and the $I^{2}$ statistic. When there was no significant heterogeneity across studies $\left(I^{2}<50 \%\right)$, the fixed effect model (Mantel-Haenszel method) was used for meta-analysis. Otherwise, the random effect model (the DerSimonian and Laird method) was used. Sources of heterogeneity were evaluated by stratification analysis, according to the study characteristics. Sensitivity analysis was performed to assess the stability of results. The publication bias was detected with Begg's test and Egger's test. $p<0.05$ was considered statistically significant.

\section{Results}

3.1. Characteristics of Eligible Studies. The detailed steps of our literature search are shown in Figure 1. A total of 57 relevant articles were retrieved from various databases, of which 36 were included after scanning the titles; 21 were removed due to duplication, 18 for irrelevance, 5 for being reviews, and 3 for unavailable data related to the association between 5HT2A T102C and psychological symptoms of Alzheimer's disease and 1 was removed for non-case-control design. Finally, 9 studies [14-17, 20, 22, 24, 26, 27] meeting the criteria were retained for meta-analysis. The basic characteristics of enrolled patients are shown in Table 1. 


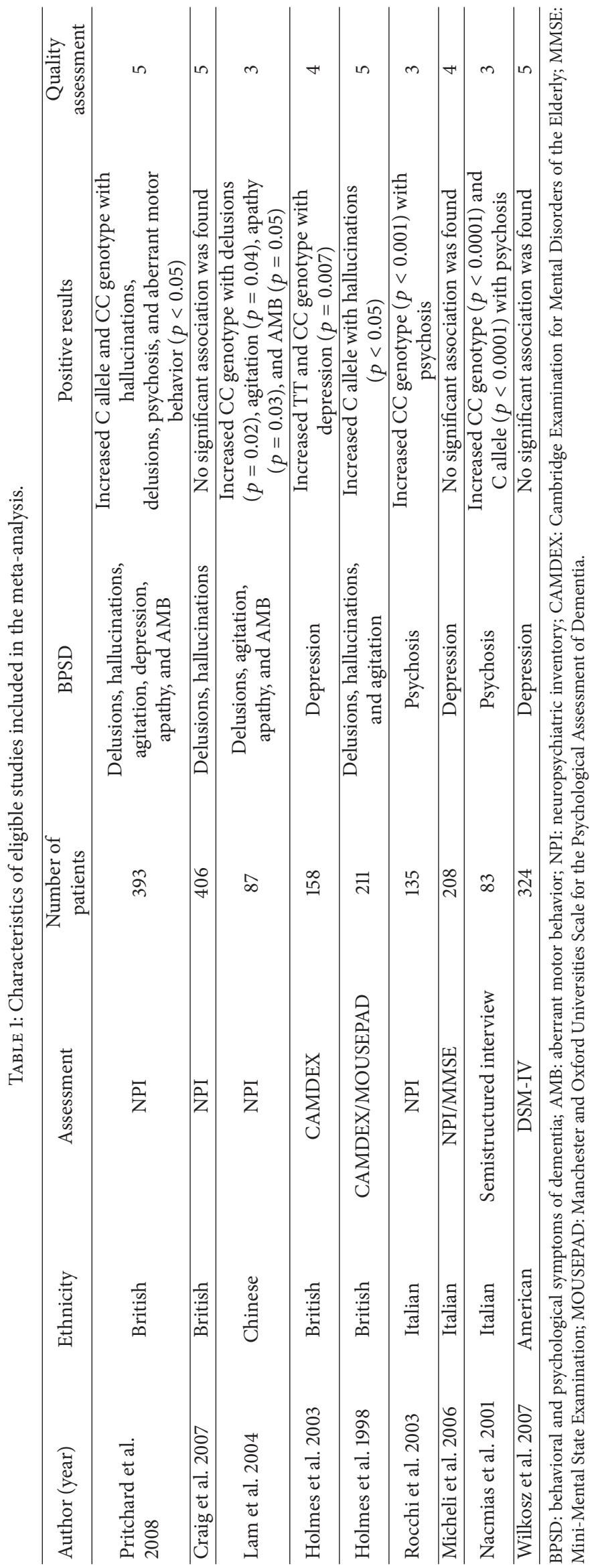




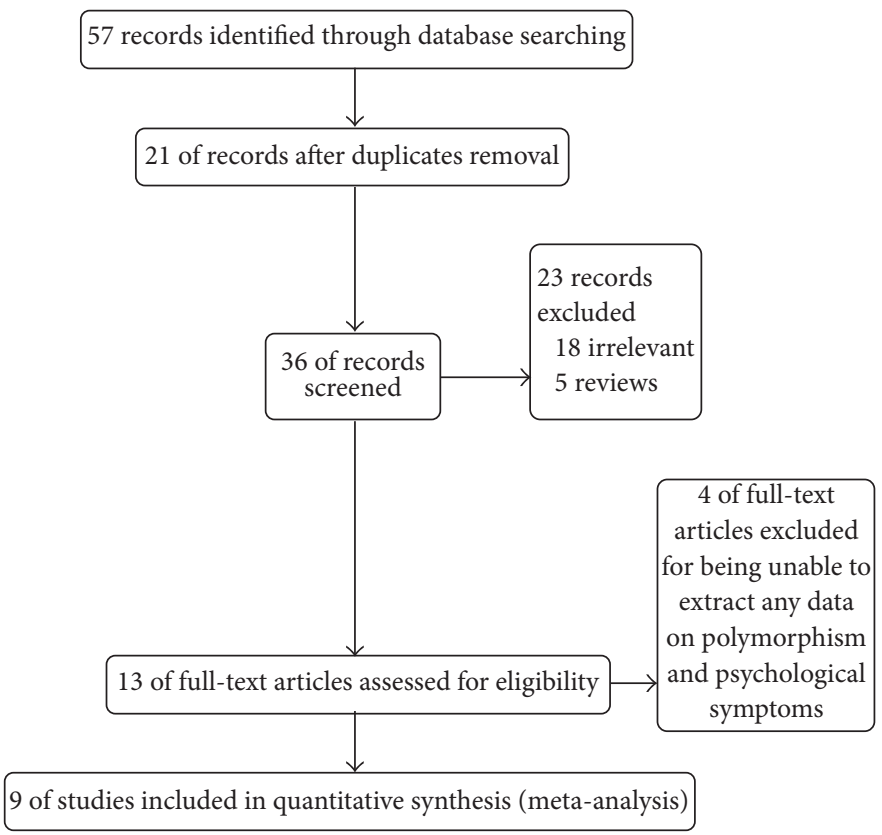

FIgURE 1: PRISMA flow chart of studies inclusion and exclusion.

TABLE 2: Pooled ORs and 95\% CIs of the association between 5HT2A T102C and psychological symptoms of Alzheimer's disease.

\begin{tabular}{|c|c|c|c|c|c|c|c|}
\hline \multirow{2}{*}{ Genetic Model } & \multirow{2}{*}{ psychological symptoms } & \multirow{2}{*}{ Number of studies } & \multicolumn{2}{|c|}{ Test of association } & \multirow{2}{*}{ Model } & \multicolumn{2}{|c|}{ Test of heterogeneity } \\
\hline & & & OR $[95 \% \mathrm{CI}]$ & $p$ value & & $p$ value & $I^{2}(\%)$ \\
\hline \multirow{7}{*}{$\mathrm{C}$ versus $\mathrm{T}$} & Delusions & 4 & $1.09[0.91-1.31]$ & 0.33 & F & 0.28 & $22 \%$ \\
\hline & Hallucinations & 3 & $1.18[0.98-1.44]$ & 0.09 & $\mathrm{~F}$ & 0.69 & $0 \%$ \\
\hline & Agitation/aggression & 3 & $0.99[0.77-1.26]$ & 0.91 & $\mathrm{~F}$ & 0.85 & $0 \%$ \\
\hline & Depression & 4 & $0.71[0.48-1.04]$ & 0.08 & $\mathrm{R}$ & 0.04 & $65 \%$ \\
\hline & Apathy & 2 & 1.31 [0.90-1.89] & 0.15 & $\mathrm{~F}$ & 0.48 & $0 \%$ \\
\hline & Aberrant motor behaviour & 2 & $1.26[0.93-1.71]$ & 0.14 & $\mathrm{~F}$ & 0.59 & $0 \%$ \\
\hline & Psychosis & 2 & 3.19 [2.12-4.79] & $<0.00001$ & $\mathrm{~F}$ & 0.62 & $0 \%$ \\
\hline \multirow{7}{*}{$\mathrm{TT}$ versus $\mathrm{CT} / \mathrm{CC}$} & Delusions & 4 & $0.81[0.59-1.11]$ & 0.20 & F & 0.80 & $0 \%$ \\
\hline & Hallucinations & 3 & $0.52[0.36-0.77]$ & 0.001 & $\mathrm{~F}$ & 0.21 & $35 \%$ \\
\hline & Agitation/aggression & 3 & $0.83[0.53-1.28]$ & 0.40 & $\mathrm{~F}$ & 0.35 & $4 \%$ \\
\hline & Depression & 4 & 1.29 [0.90-1.87] & 0.17 & $\mathrm{~F}$ & 0.27 & $23 \%$ \\
\hline & Apathy & 2 & $0.49[0.19-1.24]$ & 0.13 & $\mathrm{R}$ & 0.15 & $51 \%$ \\
\hline & Aberrant motor behaviour & 2 & $0.58[0.35-0.95]$ & 0.03 & $\mathrm{~F}$ & 0.74 & $0 \%$ \\
\hline & Psychosis & 2 & $0.34[0.17-0.67]$ & 0.002 & $\mathrm{~F}$ & 0.66 & $0 \%$ \\
\hline \multirow{7}{*}{$\mathrm{CC}$ versus TT/CT } & Delusions & 4 & $1.05[0.80-1.38]$ & 0.74 & F & 0.15 & $44 \%$ \\
\hline & Hallucinations & 3 & $1.01[0.76-1.35]$ & 0.93 & $\mathrm{~F}$ & 0.48 & $0 \%$ \\
\hline & Agitation/aggression & 3 & $0.87[0.59-1.28]$ & 0.48 & $\mathrm{~F}$ & 0.46 & $0 \%$ \\
\hline & Depression & 4 & $0.64[0.36-1.13]$ & 0.12 & $\mathrm{R}$ & 0.07 & $57 \%$ \\
\hline & Apathy & 2 & 1.08 [0.59-1.96] & 0.81 & $\mathrm{~F}$ & 0.60 & $0 \%$ \\
\hline & Aberrant motor behaviour & 2 & $0.78[0.19-3.17]$ & 0.73 & $\mathrm{R}$ & 0.08 & $66 \%$ \\
\hline & Psychosis & 2 & $7.24[3.60-14.59]$ & $<0.00001$ & $\mathrm{~F}$ & 0.21 & $37 \%$ \\
\hline
\end{tabular}

F: fixed model; R: random model; OR: odd ratio; CI: confidence interval.

3.2. Results of the Meta-Analysis. Significantly increased risk for $\mathrm{AD}$ with psychosis $(p<0.00001$, OR $[95 \% \mathrm{CI}]=$ 3.19 [2.12-4.79]) was found to be associated with 5HT2A $\mathrm{C} 102$ under the allelic model. No significant association was found between 5HT2A C102 and delusions, hallucinations, agitation/aggression, depression, apathy, and aberrant motor behavior susceptibility in the analysis as a whole (Table 2 and Figure 2). 


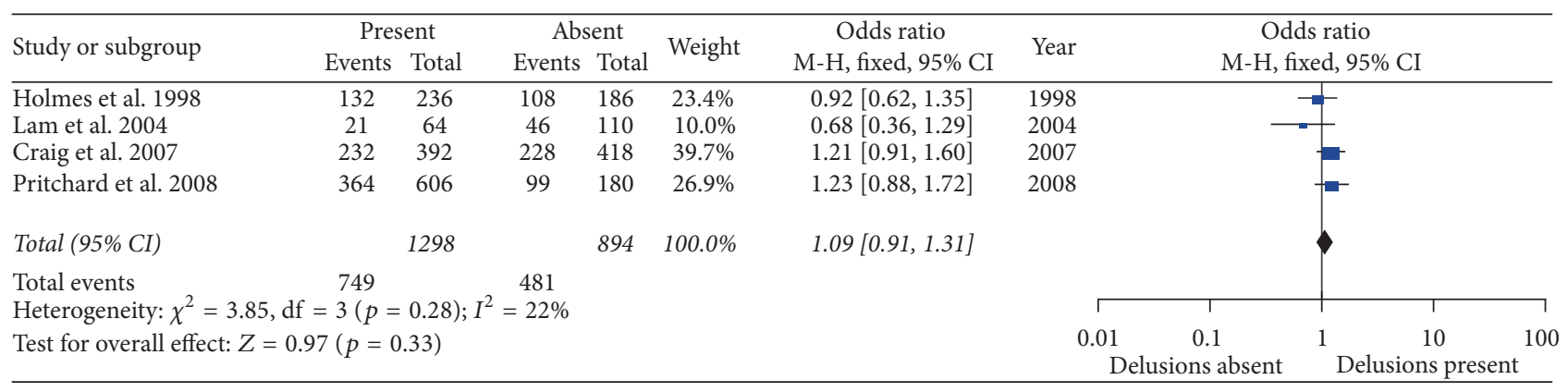

(a)

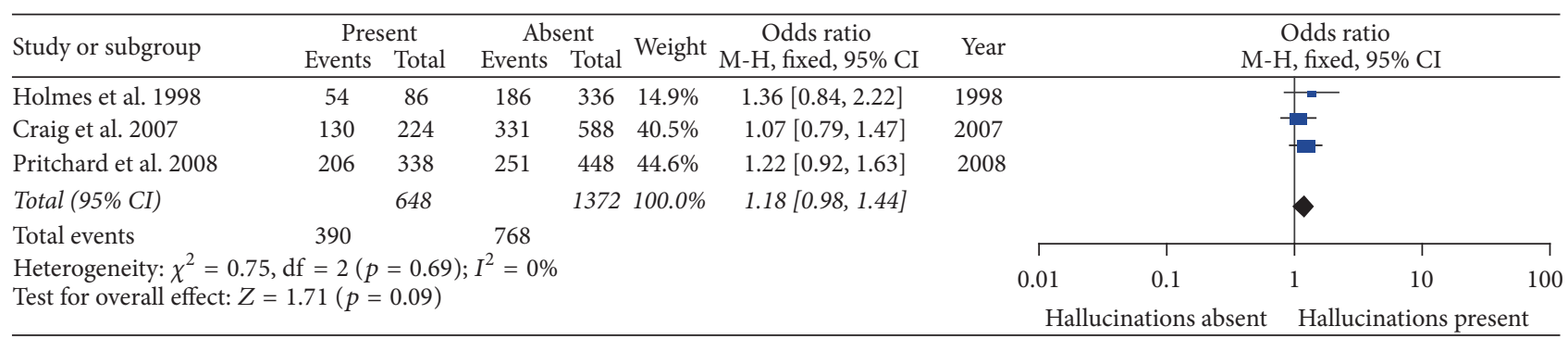

(b)

\begin{tabular}{lcccccccc}
\hline Study or subgroup & \multicolumn{2}{c}{ Present } & \multicolumn{2}{c}{ Absent } & \multirow{2}{*}{ Weight } & \multicolumn{2}{c}{ Odds ratio } \\
Events & Total & Events & Total & Year & & Odds ratio \\
M-H, fixed, 95\% CI
\end{tabular}

(c)

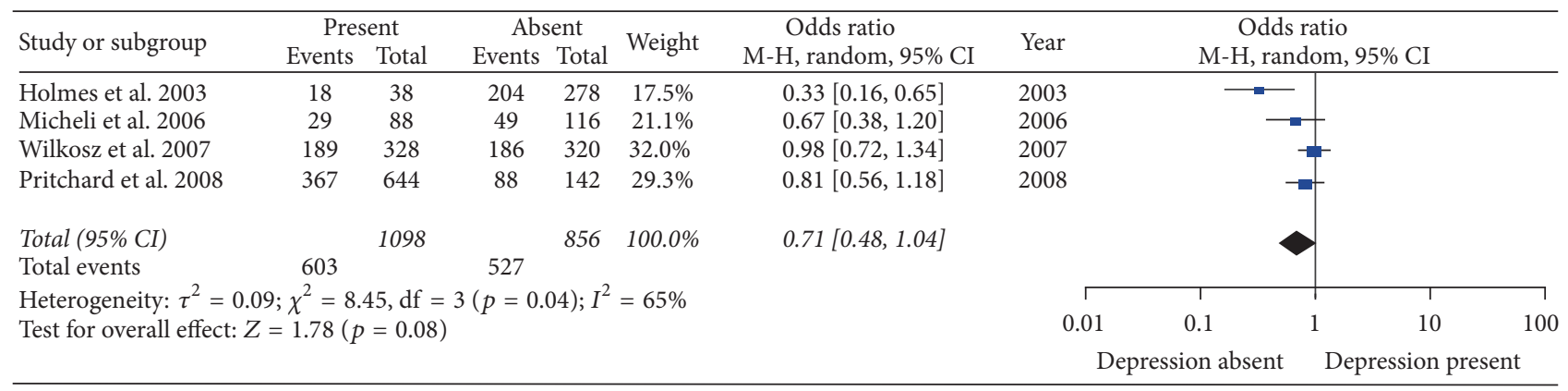

(d)

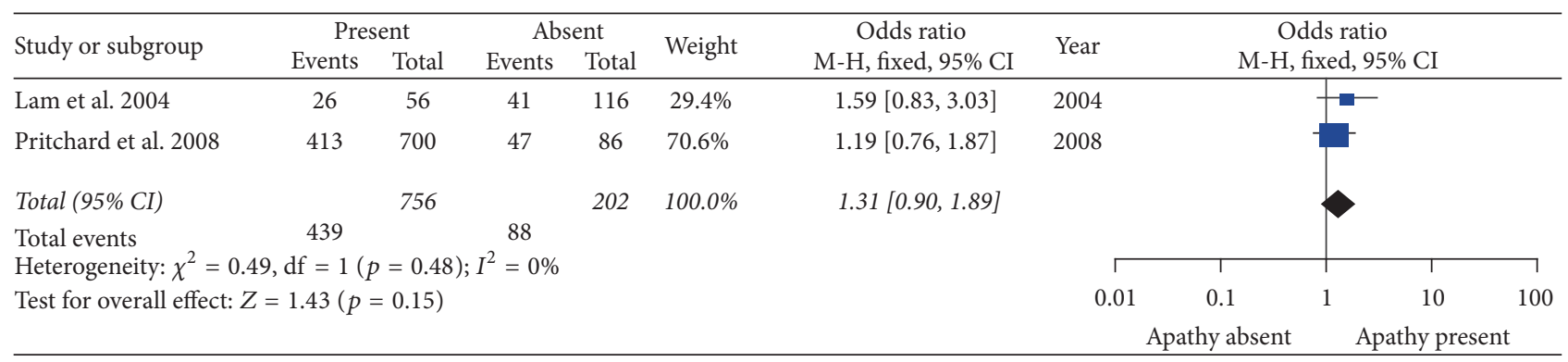




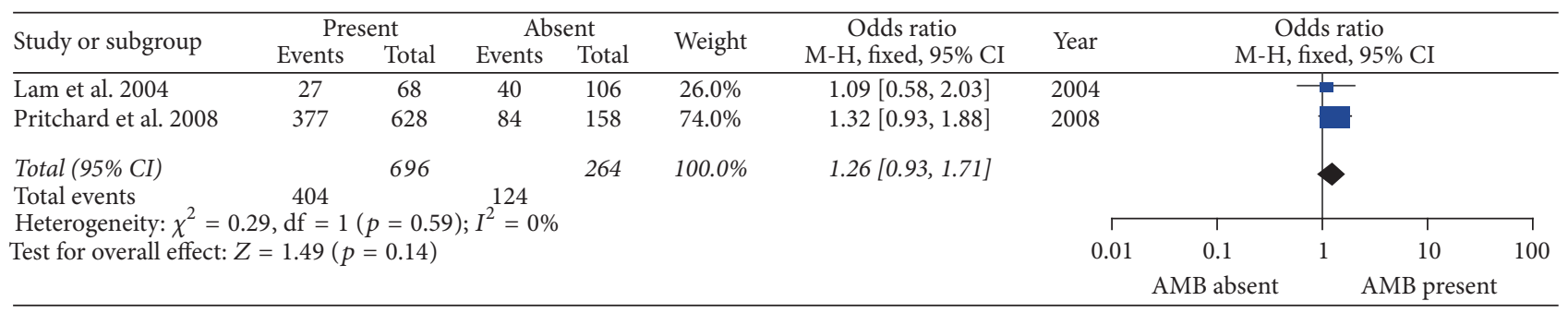

(f)

\begin{tabular}{|c|c|c|c|c|c|c|c|c|c|c|c|}
\hline \multirow{3}{*}{$\begin{array}{l}\text { Study or subgroup } \\
\text { Nacmias et al. } 2001\end{array}$} & \multicolumn{2}{|c|}{ Present } & \multicolumn{2}{|c|}{ Absent } & \multirow{2}{*}{ Weight } & \multirow{2}{*}{$\begin{array}{c}\text { Odds ratio } \\
\text { M-H, fixed, 95\% CI }\end{array}$} & \multirow{2}{*}{ Year } & \multirow{2}{*}{\multicolumn{3}{|c|}{$\begin{array}{c}\text { Odds ratio } \\
\text { M-H, fixed, 95\% CI }\end{array}$}} & \\
\hline & Events & Total & Events & Total & & & & & & & \\
\hline & $\begin{array}{l}33 \\
77\end{array}$ & $\begin{array}{c}50 \\
118\end{array}$ & $\begin{array}{l}40 \\
59\end{array}$ & $\begin{array}{l}116 \\
152\end{array}$ & $\begin{array}{l}31.4 \% \\
68.6 \%\end{array}$ & $\begin{array}{l}3.69[1.83,7.42] \\
2.96[1.80,4.88]\end{array}$ & $\begin{array}{l}2001 \\
2003\end{array}$ & & \multicolumn{2}{|c|}{$\vec{r}$} & \\
\hline \multicolumn{7}{|c|}{$\begin{array}{l}\text { Total events } \\
\text { Heterogeneity: } \chi^{2}=0.25, \mathrm{df}=1(p=0.62) ; I^{2}=0 \%\end{array}$} & $\Gamma$ & $\top$ & 1 & $T$ & \\
\hline \multicolumn{7}{|c|}{ Test for overall effect: $Z=5.59(p<0.00001)$} & 0.01 & 0.1 & 1 & 10 & 100 \\
\hline & & & & & & & \multicolumn{3}{|c|}{ Psychosis absent } & osis $\mathrm{p}$ & \\
\hline
\end{tabular}

(g)

FIGURE 2: Forest plots of odds ratios for the association between 5HT2A C102T C versus T model and the risk of psychological symptoms of Alzheimer's disease. (a) Delusions; (b) hallucinations; (c) agitation; (d) depression; (e) apathy; (f) aberrant motor behavior (AMB); (g) psychosis.

On the other hand, significant associations were found between 5HT2A T102C and hallucinations, aberrant motor behavior, and psychosis under the TT versus CT/CC model (hallucinations: $p=0.001$, OR $[95 \% \mathrm{CI}]=0.52[0.36-0.77]$; aberrant motor behavior: $p=0.03$, OR $[95 \% \mathrm{CI}]=0.58$ [0.35-0.95]; and psychosis: $p=0.002$, OR [95\% CI $]=0.34$ [0.17-0.67]). No association was observed between 5HT2A T102C and delusions, agitation/aggression, depression, and apathy susceptibility under the TT versus CT/CC model (Table 2 and Figure 3).

Furthermore, significant associations were confirmed between 5HT2A T102C and psychosis $(p<0.00001$, OR [ $95 \%$ $\mathrm{CI}]=7.24$ [3.60-14.59]) under the CC versus TT/CT model. No other evident associations between 5HT2A T102C and delusions, hallucinations, agitation/aggression, depression, apathy, and aberrant motor behavior susceptibility under the CC versus TT/CT model were observed (Table 2 and Figure 4).

3.3. Sources of Heterogeneity. Significant heterogeneity was observed between 5HT2A $102 \mathrm{C}$ and depression $\left(I^{2}=65 \%\right.$, $p=0.04)$. This heterogeneity was contributed mainly by one positive study [20]. Removal of this study from meta-analysis gave $0 \%(p=0.48)$ heterogeneity and showed that it had the highest effect on 5HT2A T102C allelic association with the effect of depression in AD.

For delusions, hallucinations, agitation/aggression, apathy, aberrant motor behavior, and psychosis, no significant heterogeneity was detected among all studies under the allelic model, TT versus CT/CC model, and CC versus TT/CT model $(p>0.05)$ (Figures 2, 3, and 4 and Table 2).
3.4. Sensitivity Analysis. A sensitivity analysis that excluded the influence of a single study on the overall risk estimate by excluding one study at a time was confirmed. The ORs were not significantly altered in the allelic model (Figure 5).

3.5. Publication Bias. Begg's test and Egger's test were used to evaluate publication bias. The $p$ value for Egger's linear regression test is shown in Table 3. Begg's test and Egger's test were not used in apathy, aberrant motor behavior, and psychosis due to a lack of sufficient data. No obvious publication bias was observed for delusions, hallucinations, or agitation/aggression $(p>0.05)$. The shape of funnel plot did not reveal any obvious asymmetry (Figure 6).

\section{Discussion}

This meta-analysis investigated the association between 5HT2A C102T and psychological symptoms in AD. The results demonstrated that the $\mathrm{C}$ allele and $\mathrm{CC}$ genotype of 5HT2A C102T were likely to be associated with psychosis in AD. The TT genotype of 5HT2A C102T was associated with hallucinations, $\mathrm{AMB}$, and psychosis in $\mathrm{AD}$.

5-HT and its receptors, particularly the 5-HT2A receptor, are considered to play a potential role in cognitive behaviors and psychiatric conditions such as depression, schizophrenia, and $\mathrm{AD}$, as suggested by a large amount of pharmacological and neurobiological evidence [13, 28-31]. Moreover, decreases in density and specific binding of the 5HT2A receptor in the frontal and temporal cortex, hippocampus, and amygdala have been identified in AD patients [3234]. Another study suggests that the presence of prominent 


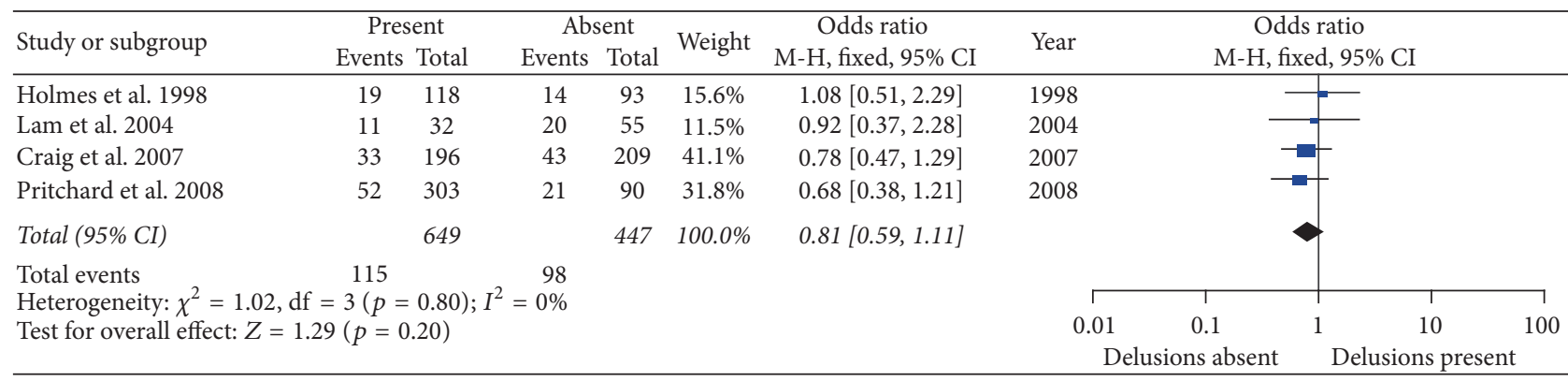

(a)

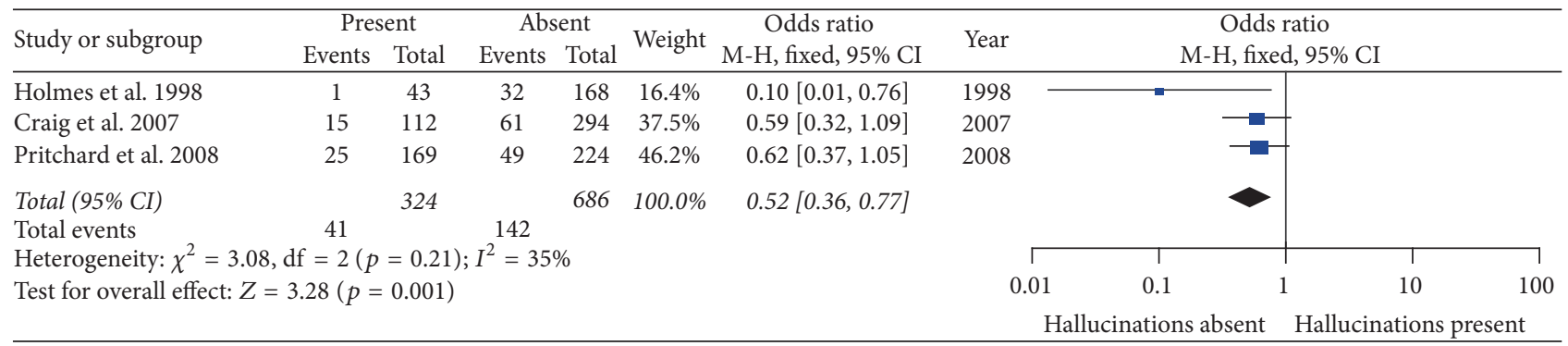

(b)

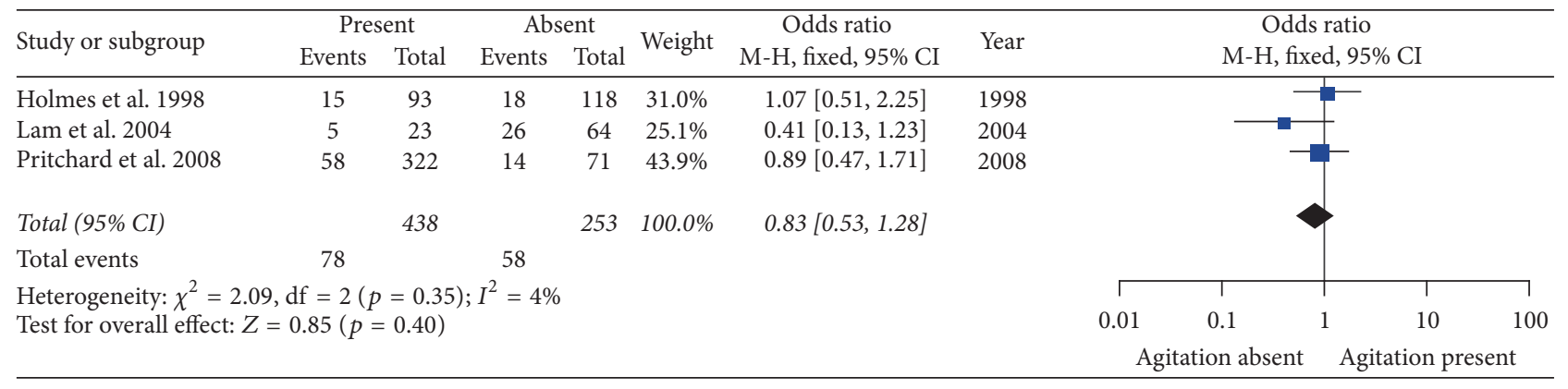

(c)

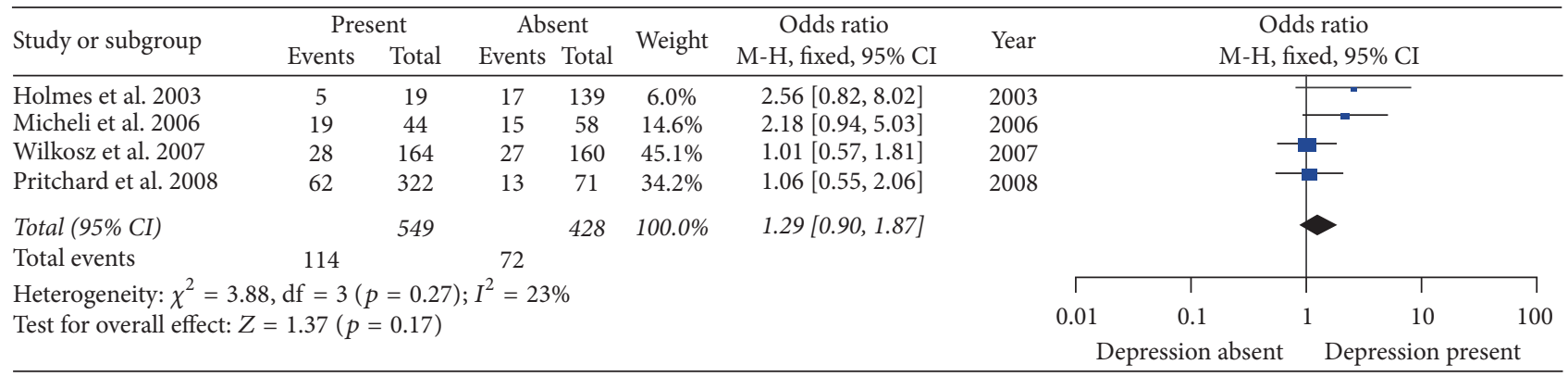

(d)

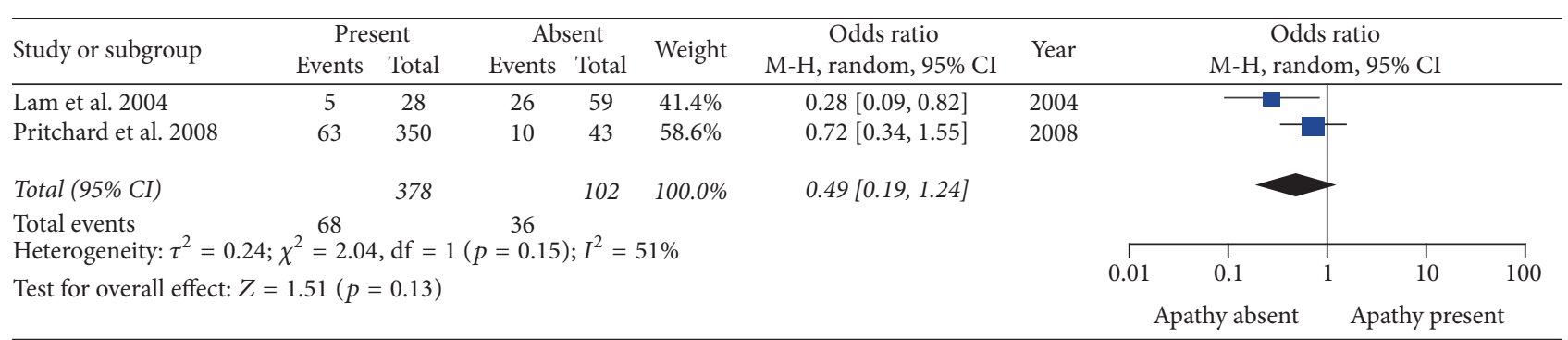

(e)

Figure 3: Continued. 


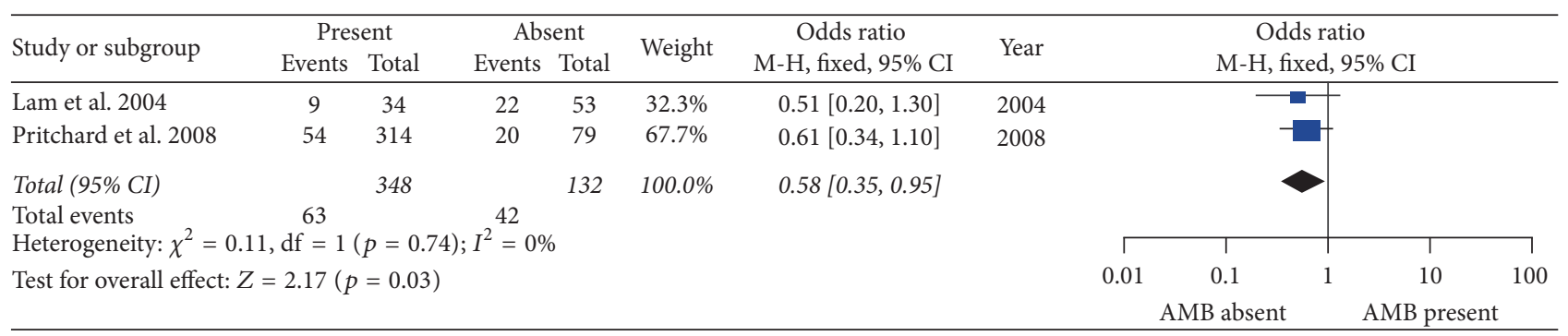

(f)

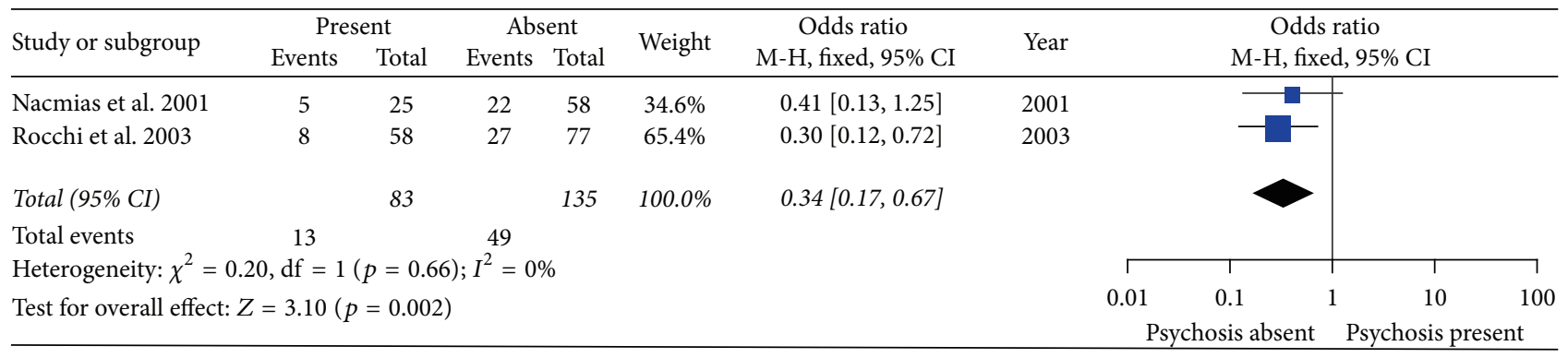

(g)

FIGURE 3: Forest plots of odds ratios for the association between 5HT2A C102T TT versus CT/CC model and the risk of psychological symptoms of Alzheimer's disease. (a) Delusions; (b) hallucinations; (c) agitation; (d) depression; (e) apathy; (f) aberrant motor behavior (AMB); (g) psychosis.

TABLE 3: Egger's linear regression test for funnel plot asymmetries of 5HT2A T102C.

\begin{tabular}{lccccccc}
\hline Groups & Delusions & Hallucinations & Agitation & Depression & Apathy $^{\mathrm{a}}$ & AMB $^{\mathrm{a}}$ & Psychosis $^{2}$ \\
\hline$p$ value & 0.638 & 0.185 & 0.442 & 0.254 & - & - & - \\
\hline
\end{tabular}

${ }^{a}$ Egger's linear regression test was cancelled in apathy, aberrant motor behavior, and psychosis for lack of sufficient data.

behavioral problems, including depression and aggressive behavior, is also associated with 5-HT2A receptor losses [35].

Many studies have examined the relationship between polymorphisms of the $5 \mathrm{HT} 2 \mathrm{~A}$ gene and $\mathrm{AD}$, as well as BPSD in $\mathrm{AD}$ patients. The mechanism by which 5 -HT2A C102T alters the action of $5-\mathrm{HT}$ in synaptic transmission remains unknown. Recent studies have shown that the TT genotype of 5HT2A C102T seems to be associated with higher platelet [36] and brain [19] 5-HT2A receptor density, which indicated an increased susceptibility for delusion symptoms in $\mathrm{AD}$ patients. In $\mathrm{AD}$, both the $102 \mathrm{~T}$ and $102 \mathrm{C}$ alleles have been linked to psychotic symptoms. Because the polymorphism was a synonymous change, most studies hypothesize that 5HT2A C102T polymorphism might be in linkage disequilibrium with other functional polymorphism(s) that may regulate and, thus, influence receptor density. This may reflect the influence of a separate gene existing in linkage disequilibrium. Notable, 5HT2A C102T polymorphism has been shown to be in linkage disequilibrium with the G1438A polymorphism in the promoter of the same gene, which could affect the expression levels of the $5 \mathrm{HT} 2 \mathrm{~A}$ receptor protein [37].
The underlying mechanism for 5-HT2A T102C in psychosis in $\mathrm{AD}$ is not well understood. It was hypothesized that increased frequency of the 5-HT2A 102C allele in APPlinked families may have further relevance in APP processing and then the BPSD in AD [38]. Two out of nine association studies have investigated the 5HT2A T102C polymorphism with psychosis and found an increase in the $\mathrm{C}$ allele or CC genotype in $\mathrm{AD}$ with psychosis $[15,16]$. A significant association was also observed between the 5HT2A C102 allele and CC genotype and psychosis in AD in our metaanalysis study, which confirms that genetic variation at the T102C locus is associated with prominent psychotic features of psychosis in $\mathrm{AD}$ and that the $102 \mathrm{C}$ allele could play an important role in the clinical course of late-onset AD. Thus, the 5HT2A C102 allele and CC genotype were risk factors in BPSD of psychosis in AD and seemed to be reliable for the higher statistic power compared to that in the previous studies with moderate sample size.

Three studies conducted the genetic association between 5-HT2A C102T and hallucinations [14, 24, 26]. Holmes et al. have reported a significant association between the 5-HT2A $\mathrm{C} 102$ allele and the presence of hallucinations (auditory and 


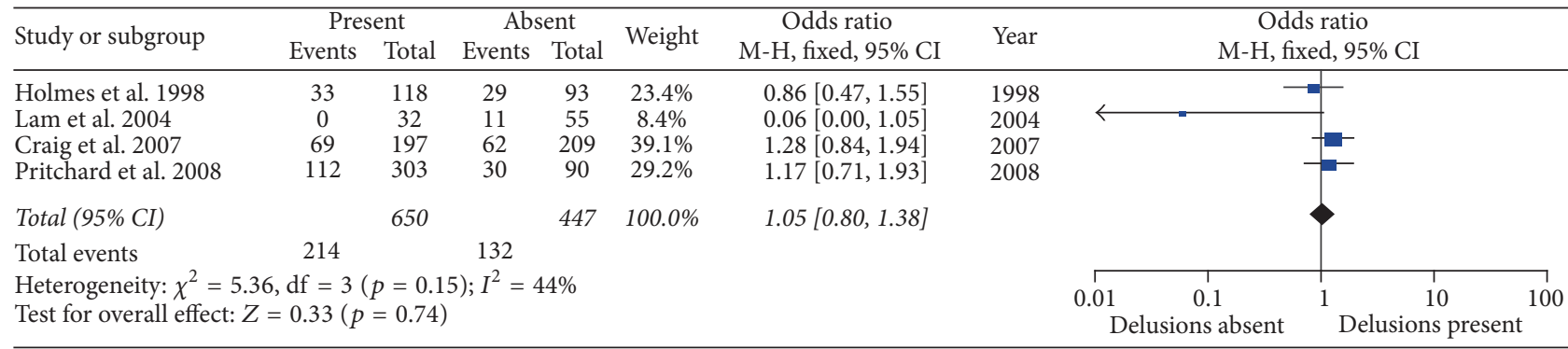

(a)

\begin{tabular}{lccccccccc}
\hline Study or subgroup & $\begin{array}{c}\text { Present } \\
\text { Events }\end{array}$ & Total & $\begin{array}{c}\text { Absent } \\
\text { Events }\end{array}$ & Total & Weight & $\begin{array}{c}\text { Odds ratio } \\
\text { M-H, fixed, 95\% CI }\end{array}$ & Year & & Odds ratio \\
M-H, fixed, 95\% CI
\end{tabular}

(b)

\begin{tabular}{lccccccccc}
\hline Study or subgroup & $\begin{array}{c}\text { Present } \\
\text { Events }\end{array}$ & \multicolumn{2}{c}{$\begin{array}{c}\text { Absent } \\
\text { Events }\end{array}$} & Total & Weight & $\begin{array}{c}\text { Odds ratio } \\
\text { M-H, fixed, 95\% CI }\end{array}$ & Year & & Odds ratio \\
M-H, fixed, 95\% CI
\end{tabular}

(c)

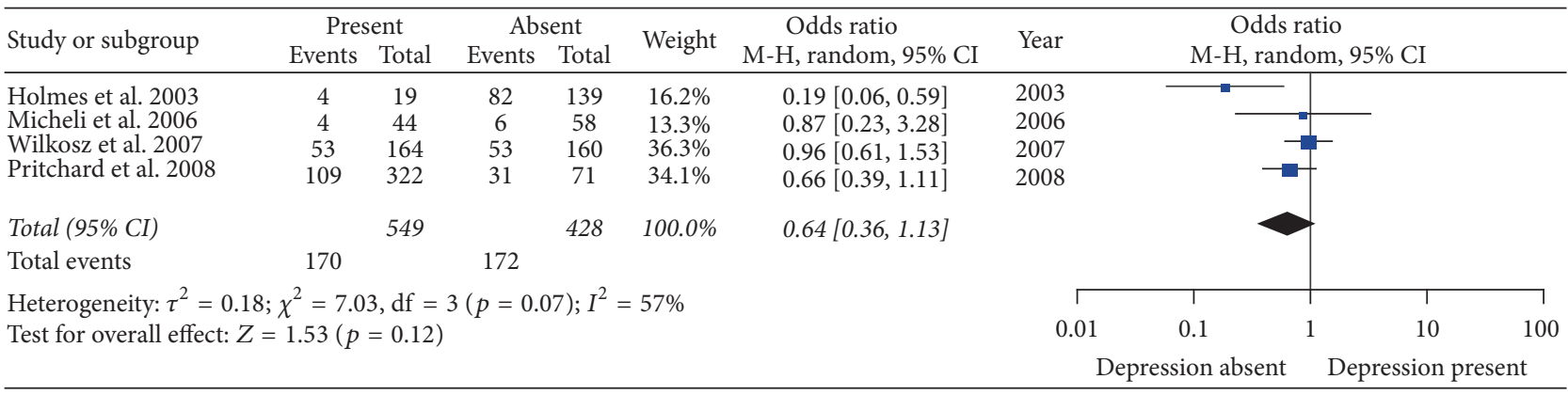

(d)

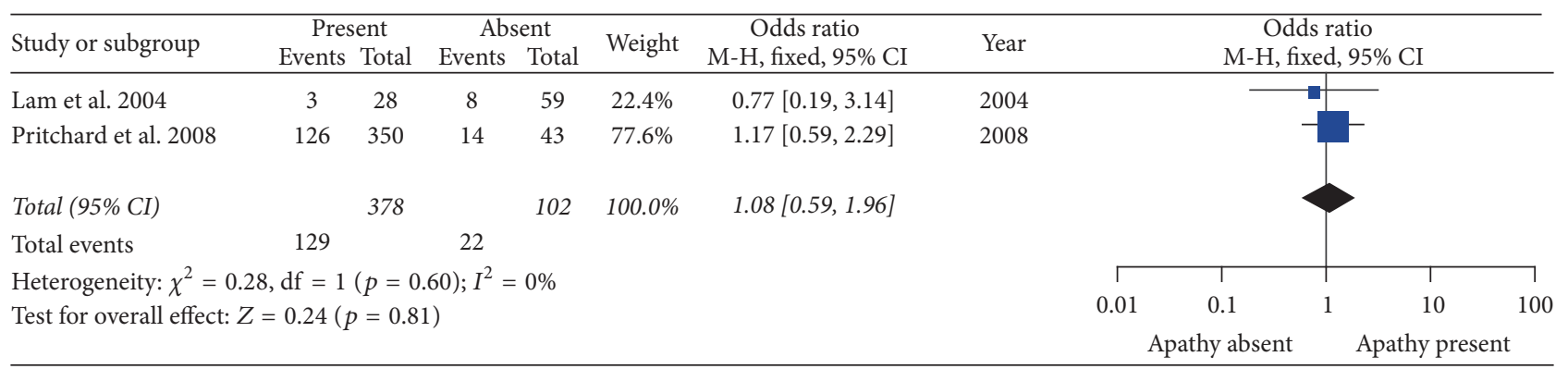

(e)

Figure 4: Continued. 


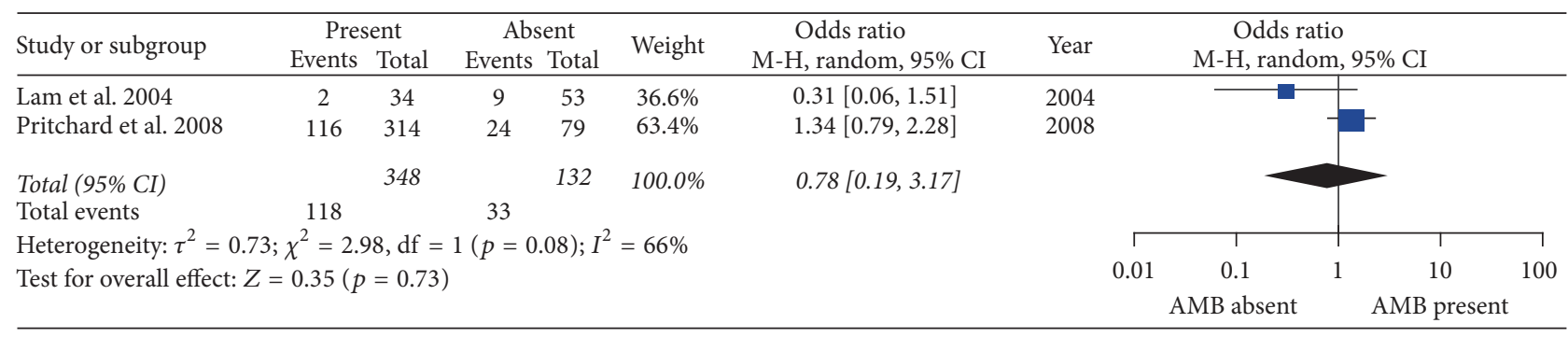

(f)

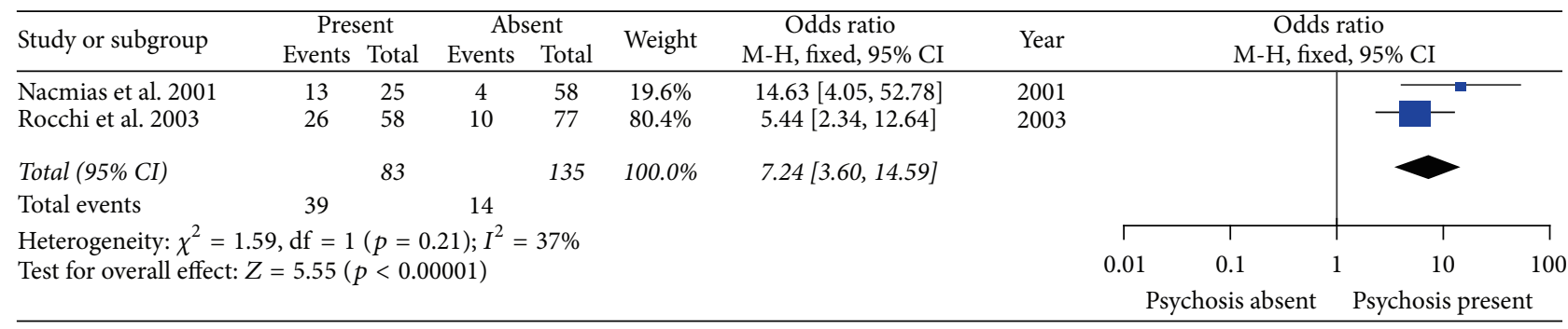

(g)

FIgURE 4: Forest plots of odds ratios for the association between 5HT2A C102T CC versus CT/TT model and the risk of psychological symptoms of Alzheimer's disease. (a) Delusions; (b) hallucinations; (c) agitation; (d) depression; (e) apathy; (f) aberrant motor behavior (AMB); (g) psychosis.

visual hallucination) in a British population [14]. However, this positive result was not replicated in other British populations $[24,26]$. And $\mathrm{AD}$ patients who are heterozygous for 5-HT2A T102C are more likely to hallucinate compared to homozygotes [14]. However, we found that the homozygotes (TT) are more likely to hallucinate compared to homozygous $\mathrm{CC}$ and heterozygous CT in AD. This contradictory finding is not easy to explain, and the inconsistent results might be due to relatively small sample sizes. Another possibility for the failure to replicate positive results could be differences in diagnostic criteria and genetic heterogeneity.

Only two previous researches reported the association between 5HT2A C102T and AMB $[17,24]$. Lam et al. observed a statistically significant increase in the CC genotype in the presence of AMB [17]. However, negative results were found by Pritchard et al. [24]. We observed a significant increase in the TT genotype, but not the CC or CT genotype, in the presence of $\mathrm{AMB}$ in this meta-analysis. The function of 5HT2A C102T in AMB is not clear. Evidence of a significant loss of 5-HT2A receptor was reported in both postmortem and in vivo studies on AD patients with prominent behavioral symptoms [20]. Moreover, selective 5HT2A antagonists inhibit the head shake and twitch induced by $5 \mathrm{HT} 2 \mathrm{~A}$ agonists in rat models, which may suggest a role of this receptor gene in the pathology of AMB [39].

We noticed that Ramanathan and Glatt [40] have conducted a meta-analysis on the association between the 5HT2A C102T and BPSDs including psychosis, delusions, and hallucinations. And significant association was only found between the 5HT2A C102 and psychosis, but not delusions, and hallucinations. Our meta-analysis included three more studies (study conducted by Assal et al. [21] was excluded for non-case-control design) with three more BPSDs (agitation/aggression, apathy, and aberrant motor behavior) and suggested a significant association between TT genotype and hallucinations in AD patients.

Limitations should be mentioned. Firstly, the number of patients was relatively small and may influence the outcomes. Only a total of nine studies were included in the present metaanalysis. Among them, 4, 3, 3, 4, 2, 2, and 2 studies are related to delusions ( 749 cases and 481 controls), hallucinations (390 cases and 768 controls), agitation/aggression (497 cases and 267 controls), depression (603 cases and 537 controls), apathy (439 cases and 88 controls), aberrant motor behavior (404 cases and 124 controls), and psychosis (110 cases and 99 controls), separately. Secondly, AD is a multifactorial disease. Gene-gene interactions may play important roles in the pathology of BPSD in AD, but most studies lack information about gene-gene interactions. Thirdly, most of the patients in the present study were Caucasians, which may limit the general application of the results to other populations.

\section{Conclusions}

The current meta-analysis suggests an increased risk of psychological symptoms of psychosis in AD for the 5HT2A C102 allele and CC genotype and a decreased risk of hallucinations, aberrant motor behavior, and psychosis in AD for the 5HT2A TT genotype. To confirm these results, further study with larger sample size and multiple ethnicities is necessary. 


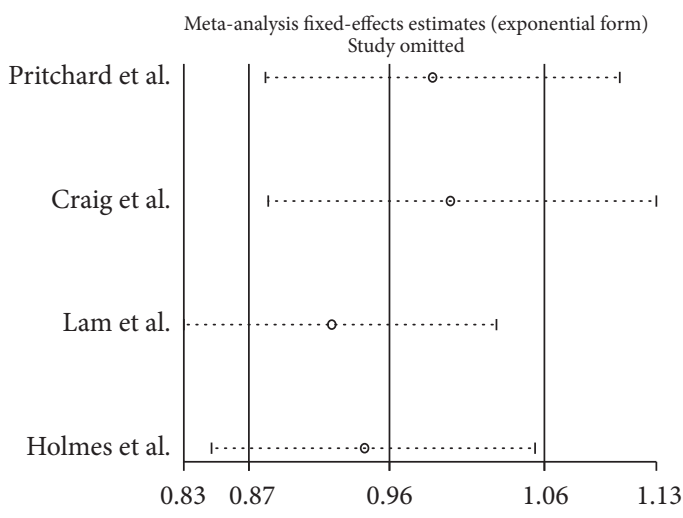

(a)

Meta-analysis fixed-effects estimates (exponential form)
Study omitted

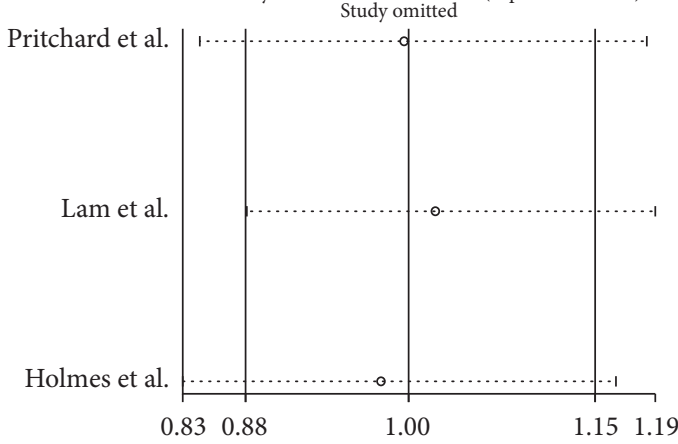

(c)

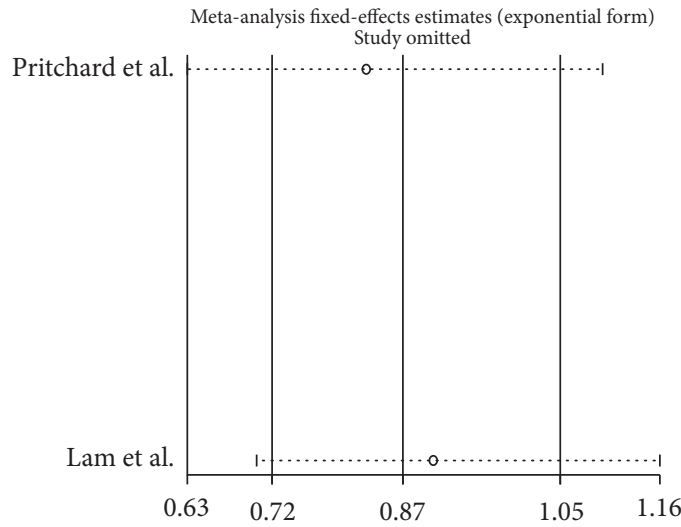

(e)

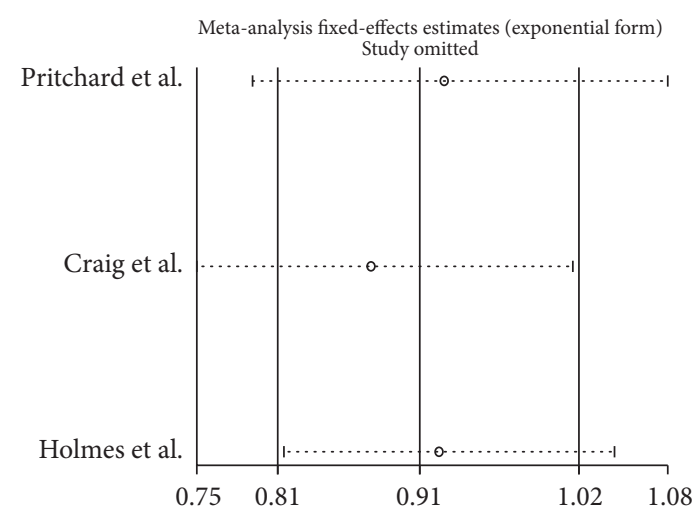

(b)

Meta-analysis fixed-effects estimates (exponential form) Study omitted

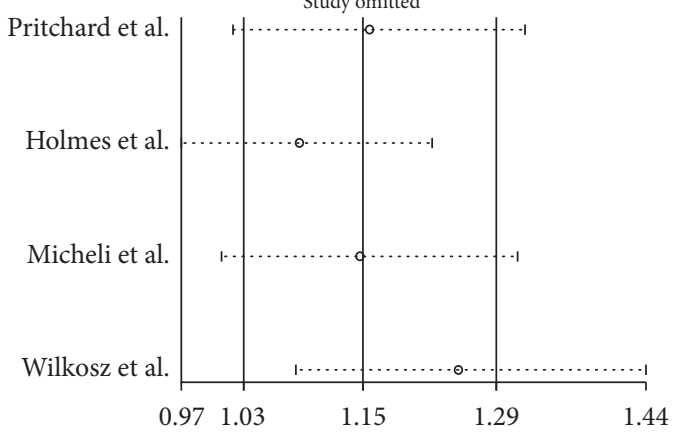

(d)

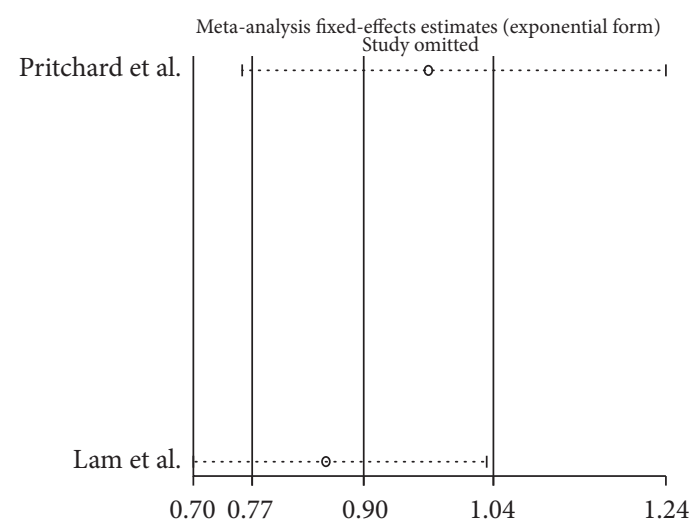

(f)

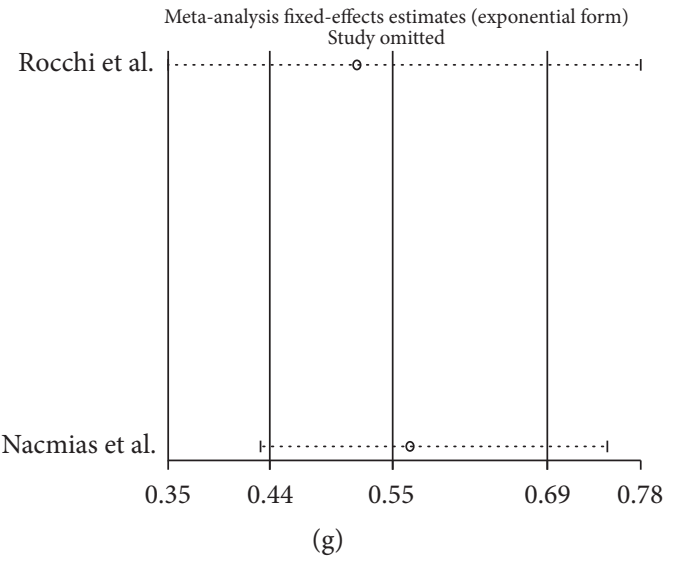

FIGURE 5: The influence of each study by removal of individual study for allelic model. (a) Delusions; (b) hallucinations; (c) agitation; (d) depression; (e) apathy; (f) aberrant motor behavior (AMB); (g) psychosis. 


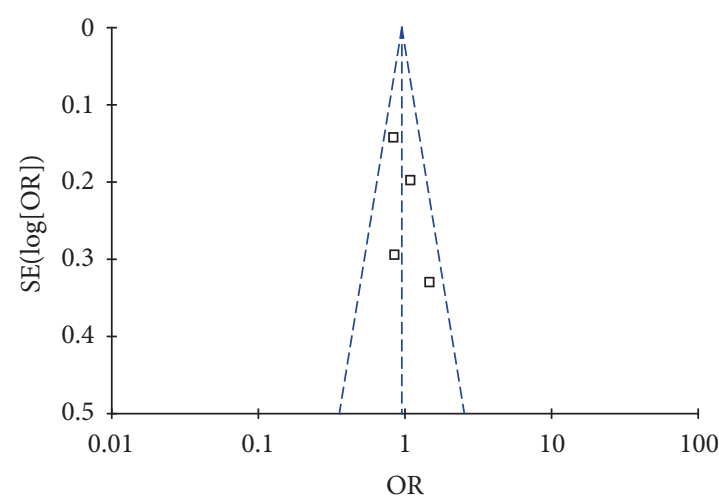

(a)

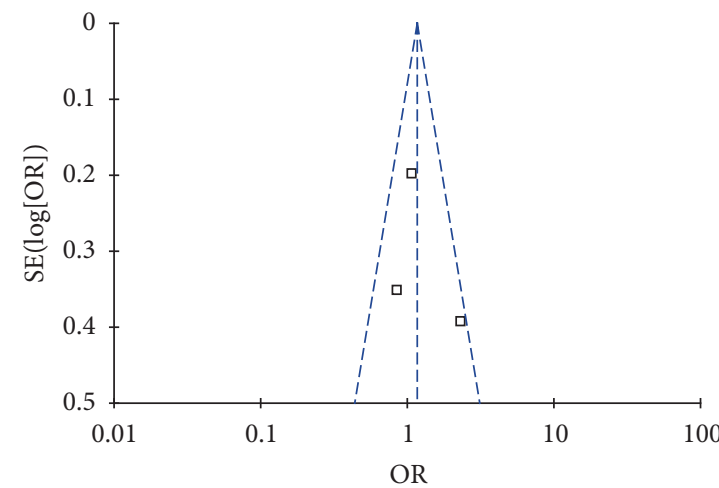

(c)

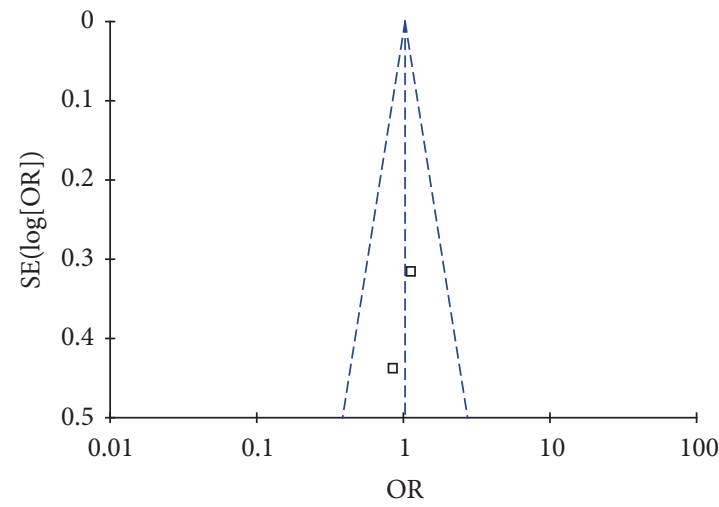

(e)

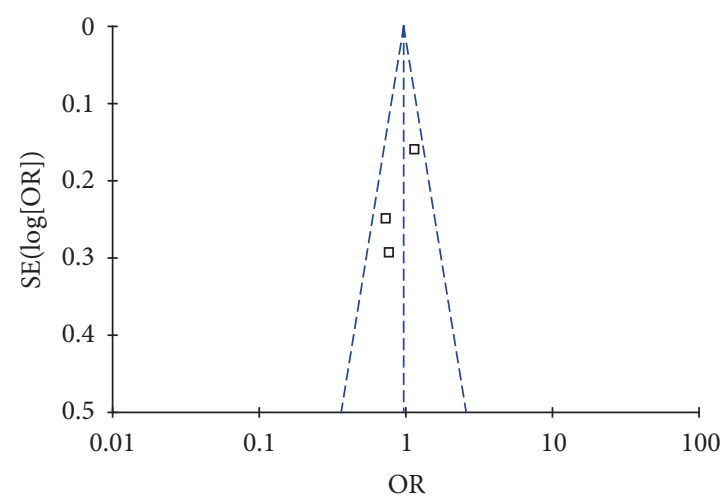

(b)

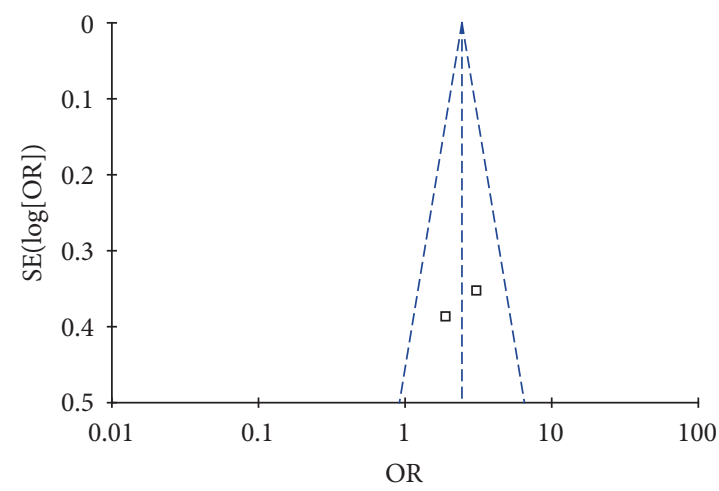

(d)

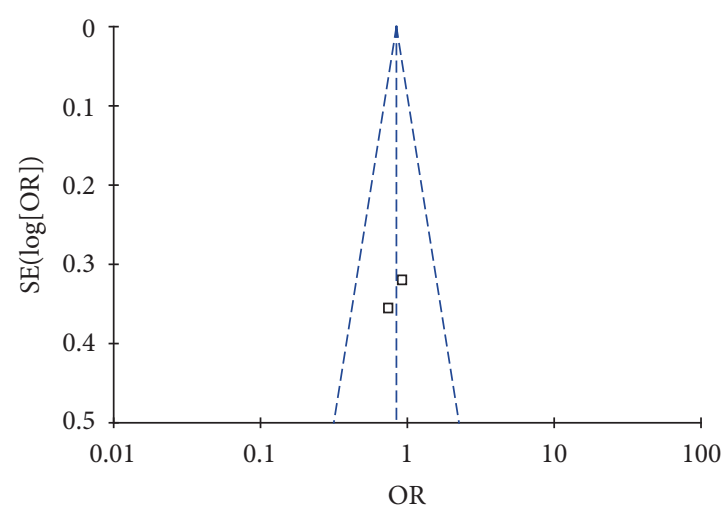

(f)

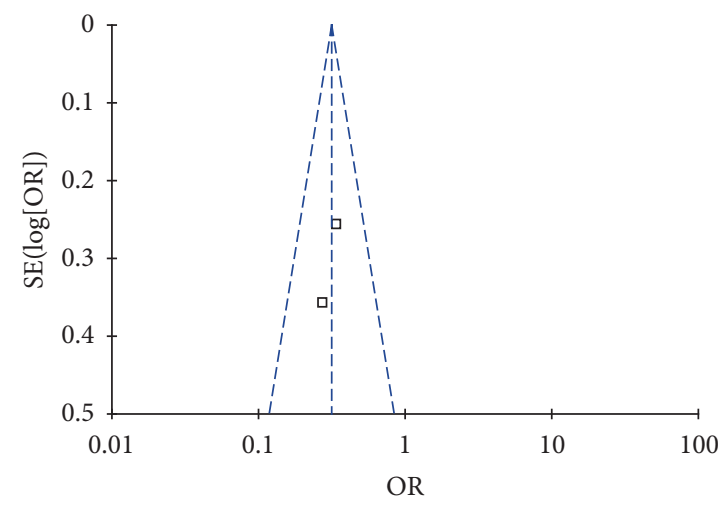

(g)

FIGURE 6: Funnel plot of publication bias for the association between 5HT2A C102T and the risk of psychological symptoms of Alzheimer's disease. (a) Delusions; (b) hallucinations; (c) agitation; (d) depression; (e) apathy; (f) aberrant motor behavior (AMB); (g) psychosis. 


\section{Conflicts of Interest}

The authors declare no conflicts of interest.

\section{Acknowledgments}

This work was funded by the Key Foundation of the Education Department of Hunan (16A027), the Foundation of the Education Department of Hunan (11C0141, 15C0513, and 16C0162), and Foundation of the Health Department of Hunan (B2016096).

\section{References}

[1] L. Xie, H. Yan, L. Shi et al., "Association between CYP17A1 rs3824755 and rs743572 gene polymorphisms and Alzheimer's disease in the Chinese Han population," Neuroscience Letters, vol. 618, pp. 77-82, 2016.

[2] R. Mushtaq, C. Pinto, S. F. Tarfarosh et al., "A Comparison of the Behavioral and Psychological Symptoms of Dementia (BPSD) in Early-Onset and Late-Onset Alzheimer's Disease - A Study from South East Asia (Kashmir, India)," Cureus, vol. 8, 2016.

[3] H. Forstl, A. Burns, R. Levy, and N. Cairns, "Neuropathological correlates of psychotic phenomena in confirmed Alzheimer's disease," The British Journal of Psychiatry, vol. 165, no. 1, pp. 5359, 1994.

[4] D. S. Strac, D. Muck-Seler, and N. Pivac, "Neurotransmitter measures in the cerebrospinal fluid of patients with Alzheimer's disease: A review," Psychiatria Danubina, vol. 27, no. 1, pp. 14-24, 2015.

[5] A. Ueki, H. Ueno, N. Sato, H. Shinjo, and Y. Morita, "Serotonin transporter gene polymorphism and BPSD in mild Alzheimer's disease," Journal of Alzheimer's Disease, vol. 12, no. 3, pp. 245253, 2007.

[6] J. Zemdegs, G. Quesseveur, D. Jarriault, L. Pénicaud, X. Fioramonti, and B. P. Guiard, "High-fat diet-induced metabolic disorders impairs 5-HT function and anxiety-like behavior in mice," British Journal of Pharmacology, pp. 2095-2110, 2016.

[7] J. H. P. van Wel, K. P. C. Kuypers, E. L. Theunissen, W. M. Bosker, K. Bakker, and J. G. Ramaekers, "Effects of acute MDMA intoxication on mood and impulsivity: role of the 5- $\mathrm{HT}_{2}$ and 5$\mathrm{HT}_{1}$ receptors," PLoS ONE, vol. 7, no. 7, Article ID e40187, 2012.

[8] H.-P. Landolt and R. Wehrle, "Antagonism of serotonergic 5HT2A/2C receptors: Mutual improvement of sleep, cognition and mood?" European Journal of Neuroscience, vol. 29, no. 9, pp. 1795-1809, 2009.

[9] J. D. A. Olivier, M. G. C. Van Der Hart, R. P. L. Van Swelm et al., "A study in male and female 5-HT transporter knockout rats: An animal model for anxiety and depression disorders," Neuroscience, vol. 152, no. 3, pp. 573-584, 2008.

[10] E. Z. McAuley, J. M. Fullerton, I. P. Blair, J. A. Donald, P. B. Mitchell, and P. R. Schofield, "Association between the serotonin $2 \mathrm{~A}$ receptor gene and bipolar affective disorder in an Australian cohort.," Psychiatric Genetics, vol. 19, no. 5, pp. 244-252, 2009.

[11] D. Li, Y. Duan, and L. He, "Association study of serotonin 2A receptor (5-HT2A) gene with schizophrenia and suicidal behavior using systematic meta-analysis," Biochemical and Biophysical Research Communications, vol. 340, no. 3, pp. 1006-1015, 2006.

[12] F. Angelucci, S. Bernardini, P. Gravina et al., "Delusion symptoms and response to antipsychotic treatment are associated with the 5-HT2A receptor polymorphism (102T/C) in alzheimer's disease: A 3-year follow-up longitudinal study," Journal of Alzheimer's Disease, vol. 17, no. 1, pp. 203-211, 2009.

[13] M. K. Lai, S. W. Tsang, J. T. Alder et al., "Loss of serotonin 5-HT2A receptors in the postmortem temporal cortex correlates with rate of cognitive decline in Alzheimer's disease," Psychopharmacology, vol. 179, no. 3, pp. 673-677, 2005.

[14] C. Holmes, M. J. Arranz, J. F. Powell, D. A. Collier, and S. Lovestone, "5-HT(2A) and 5-HT(2C) receptor polymorphisms and psychopathology in late onset Alzheimer's disease," Human Molecular Genetics, vol. 7, no. 9, pp. 1507-1509, 1998.

[15] B. Nacmias, A. Tedde, P. Forleo et al., "Association between 5-HT2A receptor polymorphism and psychotic symptoms in Alzheimer's disease," Biological Psychiatry, vol. 50, no. 6, pp. 472-475, 2001.

[16] A. Rocchi, D. Micheli, R. Ceravolo et al., "Serotoninergic Polymorphisms (5-HTTLPR and 5-HT2A): Association Studies with Psychosis in Alzheimer Disease," Genetic Testing, vol. 7, no. 4, pp. 309-314, 2003.

[17] L. C. W. Lam, N. L. S. Tang, S. L. Ma, W. Zhang, and H. F. K. Chiu, "5-HT2A T102C receptor polymorphism and neuropsychiatric symptoms in Alzheimer's disease," International Journal of Geriatric Psychiatry, vol. 19, no. 6, pp. 523-526, 2004.

[18] H. M. Abdolmaleky, S. V. Faraone, S. J. Glatt, and M. T. Tsuang, "Meta-analysis of association between the T102C polymorphism of the 5HT2a receptor gene and schizophrenia," Schizophrenia Research, vol. 67, no. 1, pp. 53-62, 2004.

[19] O. O. Polesskaya and B. P. Sokolov, "Differential expression of the "C" and "T" alleles of the 5-HT2A receptor gene in the temporal cortex of normal individuals and schizophrenics," Journal of Neuroscience Research, vol. 67, no. 6, pp. 812-822, 2002.

[20] C. Holmes, M. Arranz, D. Collier, J. Powell, and S. Lovestone, "Depression in Alzheimer's disease: The effect of serotonin receptor gene variation," American Journal of Medical Genetics Part B: Neuropsychiatric Genetics, vol. 119, no. 1, pp. 40-43, 2003.

[21] F. Assal, M. Alarcón, E. C. Solomon, D. Masterman, D. H. Geschwind, and J. L. Cummings, "Association of the serotonin transporter and receptor gene polymorphisms in neuropsychiatric symptoms in Alzheimer disease," JAMA Neurology, vol. 61, no. 8, pp. 1249-1253, 2004.

[22] D. Micheli, C. Bonvicini, A. Rocchi et al., "No evidence for allelic association of serotonin $2 \mathrm{~A}$ receptor and transporter gene polymorphisms with depression in Alzheimer disease," Journal of Alzheimer's Disease, vol. 10, no. 4, pp. 371-378, 2006.

[23] M. G. Scordo, A. Gunes, M. L. Dahl, G. Arena, E. Cordici, and E. Spina, "5-HT2A and 5-HT2C receptor polymorphisms and psychotic symptoms in Alzheimer's disease, Degenerative and neurological disorders. S572 P. 5. 5036".

[24] A. L. Pritchard, J. Harris, C. W. Pritchard et al., "Role of $5 \mathrm{HT}_{2 A}$ and $5 \mathrm{HT}_{2 \mathrm{C}}$ polymorphisms in behavioural and psychological symptoms of Alzheimer's disease," Neurobiology of Aging, vol. 29, no. 3, pp. 341-347, 2008.

[25] A. R. Jadad, R. A. Moore, D. Carroll et al., "Assessing the quality of reports of randomized clinical trials: Is blinding necessary?" Controlled Clinical Trials, vol. 17, no. 1, pp. 1-12, 1996.

[26] D. Craig, C. Donnelly, D. Hart, R. Carson, and P. Passmore, "Analysis of the 5HT-2A T102C receptor polymorphism and psychotic symptoms in Alzheimer's disease," American Journal of Medical Genetics Part B: Neuropsychiatric Genetics, vol. 144, no. 1, pp. 126-128, 2007.

[27] P. A. Wilkosz, C. Kodavali, E. A. Weamer et al., "Prediction of psychosis onset in Alzheimer disease: The role of depression 
symptom severity and the HTR2A T102C polymorphism," American Journal of Medical Genetics Part B: Neuropsychiatric Genetics, vol. 144, no. 8, pp. 1054-1062, 2007.

[28] G. Zhang and R. W. Stackman, "The role of serotonin 5-HT2A receptors in memory and cognition," Frontiers in Pharmacology, vol. 6, article no. 225, 2015.

[29] C. Xu, X.-M. Ma, H.-B. Chen, M.-H. Zhou, H. Qiao, and S.-C. An, "Orbitofrontal cortex 5-HT2A receptor mediates chronic stress-induced depressive-like behaviors and alterations of spine density and Kalirin7," Neuropharmacology, vol. 109, pp. 717, 2016.

[30] C.-C. Chang, W.-H. Fang, H.-A. Chang, T.-C. Chang, J.-F. Shyu, and S.-Y. Huang, "Serotonin 2A receptor (5-HT2A) gene promoter variant interacts with chronic perceived stress to modulate resting parasympathetic activity in humans," Psychoneuroendocrinology, vol. 76, pp. 119-126, 2017.

[31] R. Zhang, Y. Bi, W. Niu et al., "Association study of 5-HT1A, 5HT2A polymorphisms with schizophrenia and major depressive disorder in the Han Chinese population," Neuroscience Letters, vol. 635, pp. 39-43, 2016.

[32] S. Aznar and M. E. Hervig, "The $5-\mathrm{HT}_{2 A}$ serotonin receptor in executive function: implications for neuropsychiatric and neurodegenerative diseases," Neuroscience \& Biobehavioral Reviews, vol. 64, pp. 63-82, 2016.

[33] L. Marner, V. G. Frokjaer, J. Kalbitzer et al., "Loss of serotonin $2 \mathrm{~A}$ receptors exceeds loss of serotonergic projections in early Alzheimer's disease: a combined $\left[{ }^{11} \mathrm{C}\right] \mathrm{DASB}$ and $\left[{ }^{18} \mathrm{~F}\right]$ altanserin-PET study," Neurobiology of Aging, vol. 33, no. 3, pp. 479487, 2012.

[34] L. Marner, G. M. Knudsen, K. Madsen, S. Holm, W. Baaré, and S. G. Hasselbalch, "The reduction of Baseline serotonin 2A receptors in mild cognitive impairment is stable at two-year follow-up," Journal of Alzheimer's Disease, vol. 23, no. 3, pp. 453459, 2011.

[35] T. R. Morrison and R. H. Melloni, "The role of serotonin, vasopressin, and serotonin/vasopressin interactions in aggressive behavior," Current Topics in Behavioral Neurosciences, vol. 17, pp. 189-228, 2014.

[36] V. D. Khait, Y.-Y. Huang, G. Zalsman et al., "Association of Serotonin 5-HT2A receptor binding and the T102C polymorphism in depressed and healthy caucasian subjects," Neuropsychopharmacology, vol. 30, no. 1, pp. 166-172, 2005.

[37] J. Cao, X. Liu, S. Han, C. K. Zhang, Z. Liu, and D. Li, "Association of the HTR2A gene with alcohol and heroin abuse," Human Genetics, vol. 133, no. 3, pp. 357-365, 2014.

[38] H. Ueno, A. Ueki, H. Shinjo, M. Yasuda, K. Maeda, and Y. Morita, "The relationship between serotonin 2a receptor gene polymorphism and alzheimer's disease," Acta Medica Hyogoensia, vol. 32, pp. 87-93, 2007.

[39] N. M. Barnes and T. Sharp, "A review of central 5-HT receptors and their function," Neuropharmacology, vol. 38, no. 8, pp. 1083$1152,1999$.

[40] S. Ramanathan and S. J. Glatt, "Serotonergic System Genes in Psychosis of Alzheimer Dementia: Meta-Analysis," The American Journal of Geriatric Psychiatry, vol. 17, no. 10, pp. 839-846, 2009. 

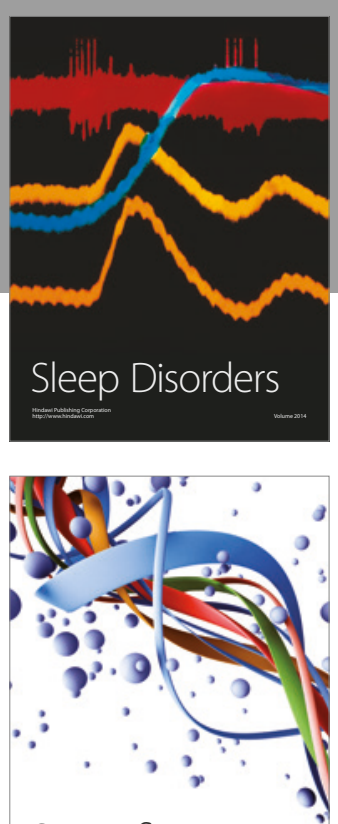

Scientifica
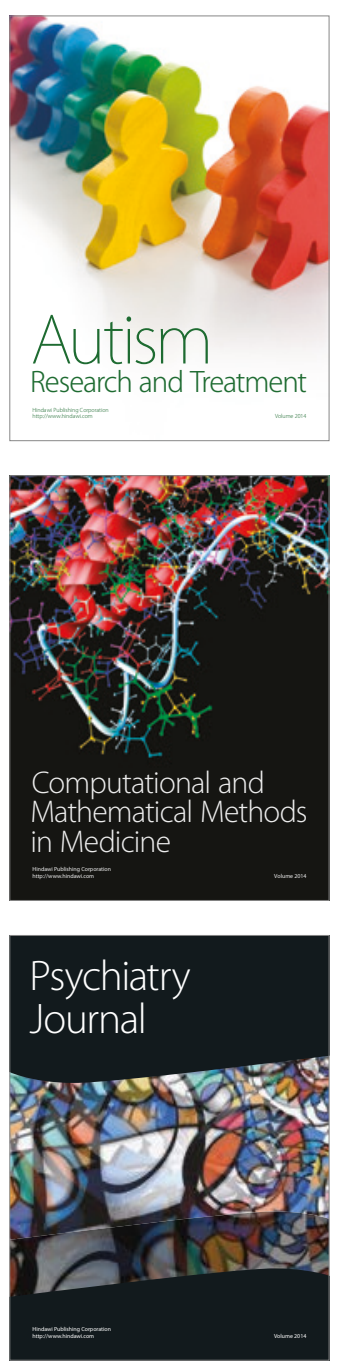
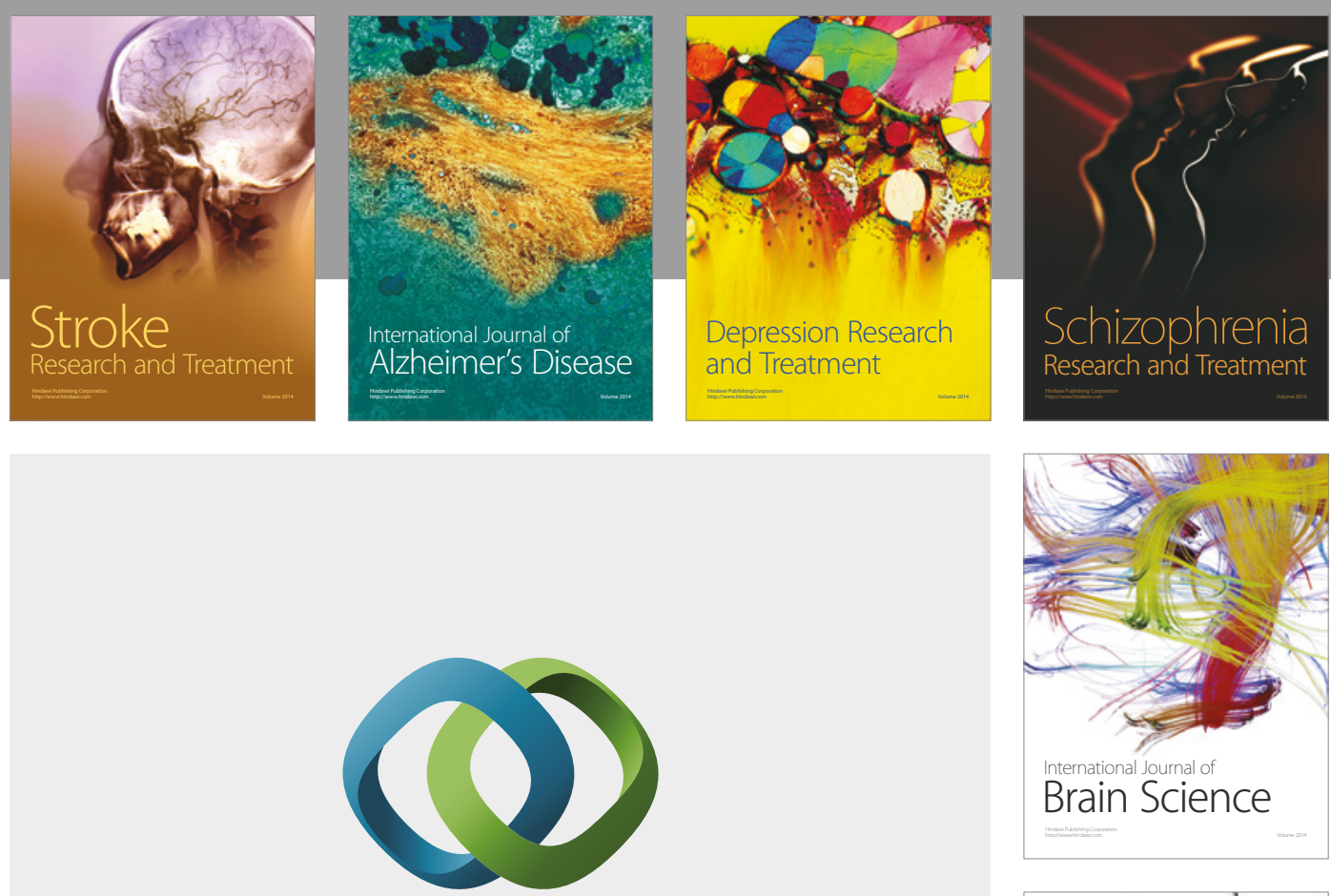

\section{Hindawi}

Submit your manuscripts at

https://www.hindawi.com
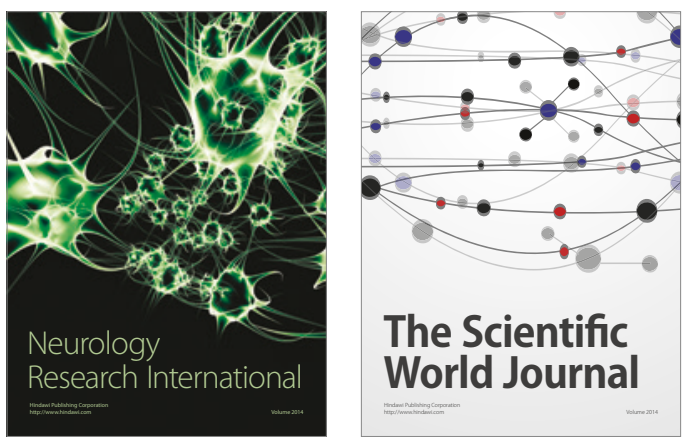

The Scientific World Journal

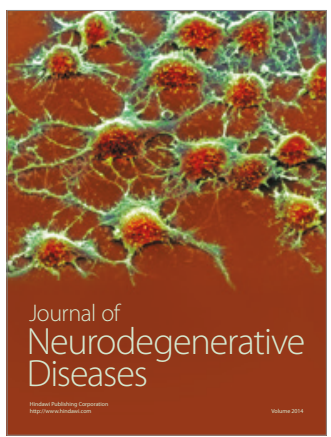

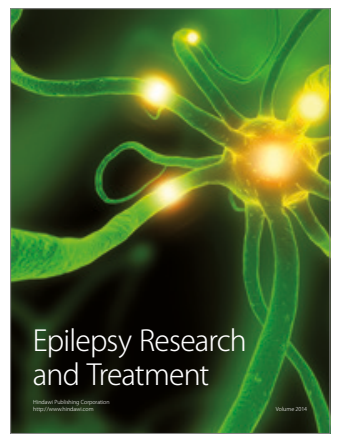

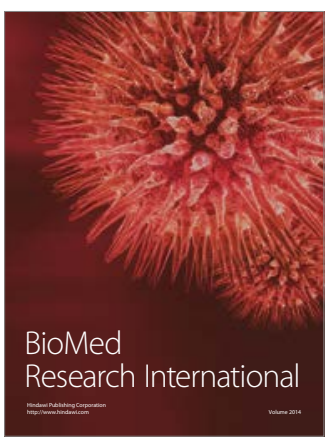

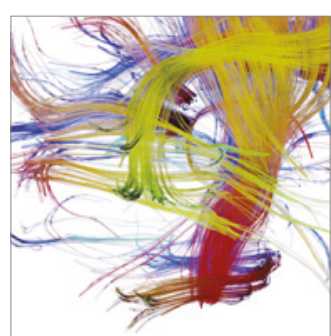

Brain Science

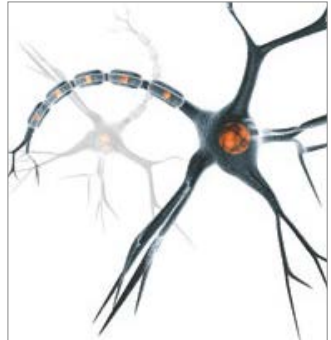

Neural Plasticity
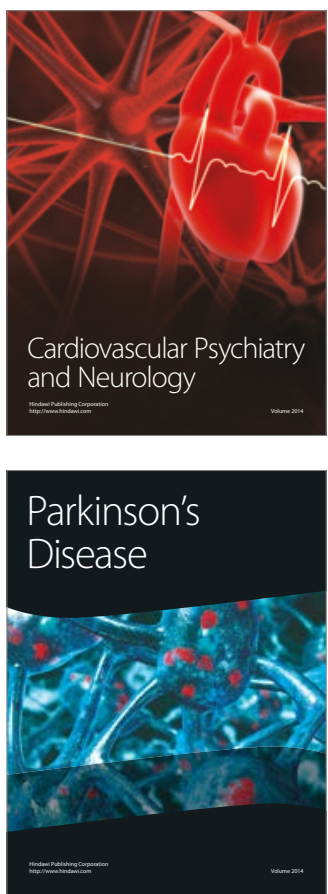